\title{
Surface Effect of Silica Nano-Particles with Different Size on Thermotropic Liquid Crystalline Polyester Composites
}

\author{
Hiroki Fukatsu1,2, Masaaki Kuno ${ }^{3}$, Yasuhiro Matsuda ${ }^{3}$, Shigeru Tasaka ${ }^{1,3}$ \\ ${ }^{1}$ Graduate School of Science and Engineering, Shizuoka University, Hamamatsu, Japan \\ ${ }^{2}$ Technical Solution Center, Polyplastics Co., Ltd., Fuji, Japan \\ ${ }^{3}$ Graduate School of Engineering, Shizuoka University, Hamamatsu, Japan \\ Email: tsctasa@ipc.shizuoka.ac.jp
}

Received 16 March 2014; revised 16 April 2014; accepted 23 April 2014

Copyright (C) 2014 by authors and Scientific Research Publishing Inc.

This work is licensed under the Creative Commons Attribution International License (CC BY). http://creativecommons.org/licenses/by/4.0/

\section{c) (i) Open Access}

\begin{abstract}
Interface properties of nano-silica/thermotropic liquid crystalline polyesters (TLCP) composites were investigated by X-ray diffraction analysis and differential scanning calorimetory. The crystallinity of TLCP in the composites drastically decreased with an increase of nano-silica content, depending on the surface area of the silica particles. Little size effects $(40-400 \mathrm{~nm})$ in the particles and strong interaction between silica surface and the $\mathrm{C}=0$ moieties of TLCP were observed by IR analysis. The glass transition temperature of TLCP $(<20 \mathrm{~nm})$ in silica surface increased about $20^{\circ} \mathrm{C}$ higher than that in bulk.
\end{abstract}

\section{Keywords}

Component, Nano-Silica, Thermotropic Crystalline Polyester, Interface, Differential Scanning Calorimetry

\section{Introduction}

Thermotropic main-chain liquid crystalline polymers (TLCPs) usually have rigid main chains and good mechanical properties, high chemical and thermal stability, which make TLCPs high performance engineering plastics widely used for electronics, automotive and aerospace applications [1]. The main chains of molten TLCPs align spontaneously for their rigidity [2], and this orientated structure affects the excellent physical and chemical properties of TLCP. In general, such as glass fibers (GFs), or mineral fillers are added to TLCP to improve dimensional stability, thermal properties and processability of neat TLCP. In order to achieve above properties, understanding the mutual interaction at the interface between the inorganic filler and TLCP is important.

How to cite this paper: Fukatsu, H., et al. (2014) Surface Effect of Silica Nano-Particles with Different Size on Thermotropic Liquid Crystalline Polyester Composites. World Journal of Nano Science and Engineering, 4, 35-41. 
There have been many studies on the influence of various kinds of fillers; GFs or carbon fibers (CFs) to reduce the anisotropy of TLCPs [3]-[8]. Bhama and Stupp [7] synthesized a random terpolymer of p-acetoxybenzoic acid, diacetoxyhydroquine, and pimelic acid, and added CFs to investigate the interfacial structure of this TLCP. The orientation time of the TLCP determined by NMR was decreased by adding only $1 \mathrm{wt} \%$ of CFs, and polarizing optical micrographs (POM) of the composites of the TLCP and CFs indicated that the orientation rate of the TLCP was enhanced at the interfacial zones.

Lee et al. [8] prepared composites of a copolymer composed of 70 mol\% of 4-hydroxybenzoic acid (HBA) and $30 \mathrm{~mol} \%$ of 6-hydroxy-2-naphthoic acid (HNA) and GFs. To investigate the influence of chemical interaction between TLCP and GFs, they used three types of GFs; GFs treated with $\gamma$-methacrylate propyltrimethoxysilane ( $\gamma$-MPS), which reacts with the TLCP, GFs treated with phenyltriethoxysilane (PTS) which does not react with the TLCP, and GFs without any treatments. A thin layer of TLCP with banded optical texture parallel to GFs was identified in the composite of TLCP and untreated GFs based on the experimental results of POM, scanning electron micrography, and X-ray diffractometry (XRD). This thin layer was induced by the guiding, anchoring, and packing effects of GFs. The same thin layer was also observed in the composite of TLCP and GFs treated with $\gamma$-MPS, but there was only thinner layer where TLCP randomly arranged in the composites of TLCP and GFs treated with PTS.

The conventional thermal analysis (DSC), X-ray diffraction (XRD) can obtain even enough interface information to increase the surface area by adding an excess of heterogeneous material in the polymer in our laboratory. Then unique phenomenon was observed in TLCP and SNPs with different sizes [9]-[11]. Our final purpose is to provide a novel TLCP composite with various fillers which obtained interfacial information by the conventional method. Comparing the researches on the influence of adding fiber on the properties of TLCP, there have been much fewer reports on the effect of adding nano-particles on the properties of TLCPs.

It is expected to be difficult for the rigid chains of TLCPs to align at the curved surfaces of nano-particles, while it is easy for the rigid chains of TLCPs to align parallel to the fibers. The rigid chains of TLCPs in composites with nano-particles may be forced to form structure which is different from the structure of TLCPs without fillers. This suggests that the influence of nano-particles on the properties of TLCPs can be different from that of fibers.

In this study, XRD, IR, differential scanning calorimetry (DSC) and dynamic mechanical analysis (DMA) were carried out for composites of a copolymer of HBA and HNA, and SNPs with different sizes to investigate the size effect of SNPs with on the interfacial structural of this TLCP.

This template, created in MS Word 2007, provides authors with most of the formatting specifications needed for preparing electronic versions of their papers. All standard paper components have been specified for three reasons: 1) ease of use when formatting individual papers, 2) automatic compliance to electronic requirements that facilitate the concurrent or later production of electronic products, and 3) conformity of style throughout a journal paper. Margins, column widths, line spacing, and type styles are built-in; examples of the type styles are provided throughout this document and are identified in italic type, within parentheses, following the example. Some components, such as multi-leveled equations, graphics, and tables are not prescribed, although the various table text styles are provided. The formatter will need to create these components, incorporating the applicable criteria that follow.

\section{Experimental}

The TLCP used in this study is VECTRA A950 supplied by Polyplastics Co. Ltd, which is composed of 73 mol\% of HBA and 27 mol\% of HNA. The chemical structure of this TLCP is shown in Figure 1. The weight average molecular weight and molecular weight distribution of VECTRA A950 were reported to be 30,000 [12], and 2.45 [13], respectively. The random sequence distribution of this sample was also confirmed [14]-[19]. SNPs with average diameter of $51 \mathrm{~nm}$ were purchased from Kanto Chemical, and those with average diameter of 240 and $485 \mathrm{~nm}$ were the products of Amatecs. SNPs were dried for an hour in a vacuum oven heated at $300^{\circ} \mathrm{C}$ to remove adsorbed water. The densities of the TLCP and SNPs are $1.4 \mathrm{~g} \cdot \mathrm{cm}^{-3}$, and $2.2 \mathrm{~g} \cdot \mathrm{cm}^{-3}$, respectively.

The composites of the TLCP and SNPs were prepared by melt-compounding with a twin screw melt mixer (Labo-plastmill 4C150-01, Toyo Seiki Seisaku-sho) at $300^{\circ} \mathrm{C}$ for $8 \mathrm{~min}$. The screw rotation speed was $100 \mathrm{rpm}$, 


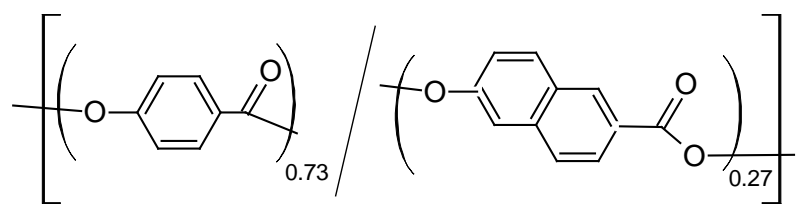

Figure 1. Chemical structure of TLCP used in this study.

and the final rotating torque of mixing was saturated under this condition. The contents of SNPs in the composites were confirmed with a thermogravimetric analyzer (TGA Q-500, TA Instruments). The films of the composites for the measurements were prepared by hot-pressing at $300^{\circ} \mathrm{C}$, and then cooled slowly at room temperature.

The thermal properties of the composites were measured with a Q1000 calorimeter manufactured by TA Instruments calibrated with analytical grade indium. The samples were heated and cooled at the rate of $10^{\circ} \mathrm{C} / \mathrm{min}$ under nitrogen atmosphere. XRD was carried out at room temperature with a RINT2500 manufactured by Rigaku using $\mathrm{Cu} \mathrm{K} \alpha$ radiation as an X-ray source. Fourier transfer Infrared (FTIR) spectra were obtained using a FTIR-8900 of Shimadzu device of resolution $4 \mathrm{~cm}^{-1}$. Dynamic mechanical measurement (DMA) was performed by a rheometric solids analyzer RSA III (Rheometric Scientific). The measurements were carried out in tensile mode, both the frequency (Fr) and the strain amplitude $(\gamma)$ are kept constant in each test interval; the only variable parameter is temperature. The samples were heated with a ramp rate of $5{ }^{\circ} \mathrm{C} / \mathrm{min}$ at constant $\gamma=0.1 \%$ and $\mathrm{Fr}$ $=1 \mathrm{~Hz}$ under a nitrogen environment.

\section{Results and Discussion}

Figure 2 shows XRD patterns for the composites of TLCP and SNPs with different diameters. The fraction of SNPs was fixed to be $50 \mathrm{wt} \%$ (39 vol\%). The sample designated as "Unfilled” is TLCP without SNPs. The intensity of the peak at $19.5^{\circ}$, which is caused by the psudeohexagonal structure of VECTRA A950 [20] [21], was decreased by adding SNPs. SNPs with smaller diameter decreased the peak intensity more significantly, and the same tendency was also measured for the composites with different weight fraction of SNPs. This result suggests smaller SNPs prevent the formation of crystal structure of TLCP. The heating and cooling curves of DSC for the composites of TLCP and SNPs with different diameters are shown in Figure 3. The endothermic peak at $280^{\circ} \mathrm{C}$ in the heating curve and exothermic peak at $230^{\circ} \mathrm{C}$ in the cooling curve are caused by the phase transition from crystal to nematic and from nematic to crystal, respectively. Both the endothermic peak and exothermic peak became weaker by adding SNPs with smaller diameters. In addition, the abrupt change of the specific heat around $90^{\circ} \mathrm{C}$ is caused by the glass transition of the amorphous regions of TLCP. The change of the specific heat around the glass transition temperature (Tg) became more significant by adding SNPs with smaller diameters. Moreover, Tg decreases with an increase of amorphous contents, and increases more than $20^{\circ} \mathrm{C}$ with further adding SNPs of $51 \mathrm{~nm}$. These DSC results suggest that smaller SNPs prevent the formation of crystal structure of the TLCP and increase the amorphous region, which was supported by the results of XRD. Figure 4 and Figure 5 summarize the results of DSC for the composites of the TLCP and SNPs. $\Delta \mathrm{Hm}$ and $\Delta \mathrm{Cp}$ are the heat of fusion at $280^{\circ} \mathrm{C}$ and the change of the specific heat at $90^{\circ} \mathrm{C}$, respectively. These clearly show a decrease of $\Delta \mathrm{Hm}$ and an increase of $\Delta \mathrm{Cp}$ by adding SNPs, and smaller SNPs was influenced on the changes of $\Delta \mathrm{Hm}$ and $\triangle \mathrm{Cp}$. The results of XRD and DSC showed that the addition of SNPs to the composite of the TLCP and SNPs prevents the crystallization and induces the formation of amorphous regions of the TLCP, and that these tendencies became more significant when SNPs with smaller sizes were used for the sample preparation. This type of interfacial structures has been seen in polyamide/nano-silica composites [22]. Figure 6 shows IR changes of $\mathrm{C}=\mathrm{O}$ stretching band sift for the composites of TLCP/SNPs. The doublet bands $\left(\sim 1740 \mathrm{~cm}^{-1}\right)$ in TLCP and shift to lower and higher wave numbers with broadening, and changed in strength by mixing with SNPs. This behavior has no size dependences of SNPs in range of this experiment. The $\mathrm{C}=\mathrm{O}$ groups get two states in amorphous. One is a constrained state and the other is a relatively free state. This means that a part of the C=O groups in TLCP chain is strongly bound in the surface of SNPs. Figure 7 shows storage modulus (a) and tan $\delta$ (b) for the composites of the TLCP and SNPs with different size as a function of temperature. The storage modulus of smaller SNPs showed much lower and especially drastic decrease over $150^{\circ} \mathrm{C}$. This result showed that stiffness decreased at high temperature due to increase of the amorphous region and decrease of the crystalline region as 


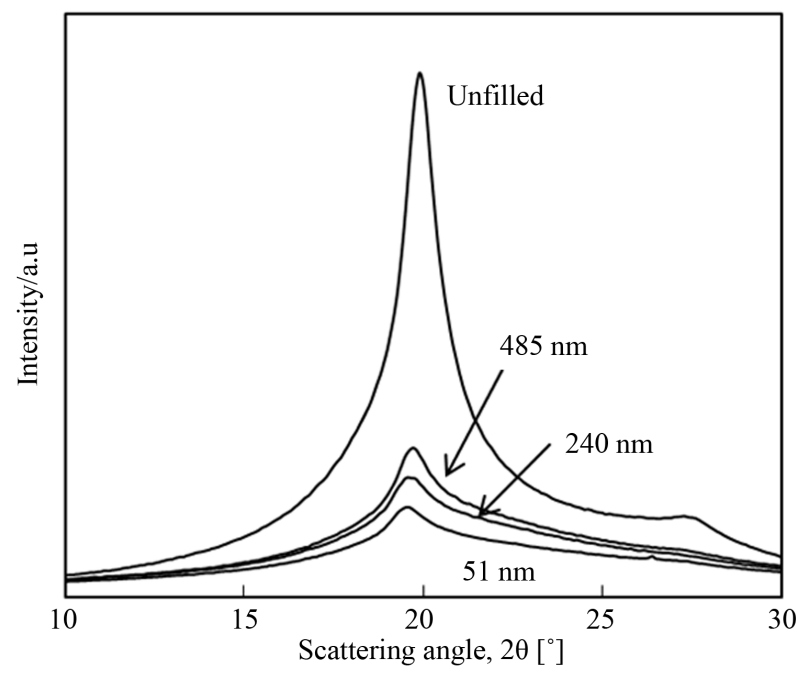

Figure 2. XRD patterns of the composites of TLCP and SNPs with different diameters indicated in the figure. The weight fraction of SNPs was fixed to be $50 \%$. The sample designated as "Unfilled" indicates TLCP without SNPs.

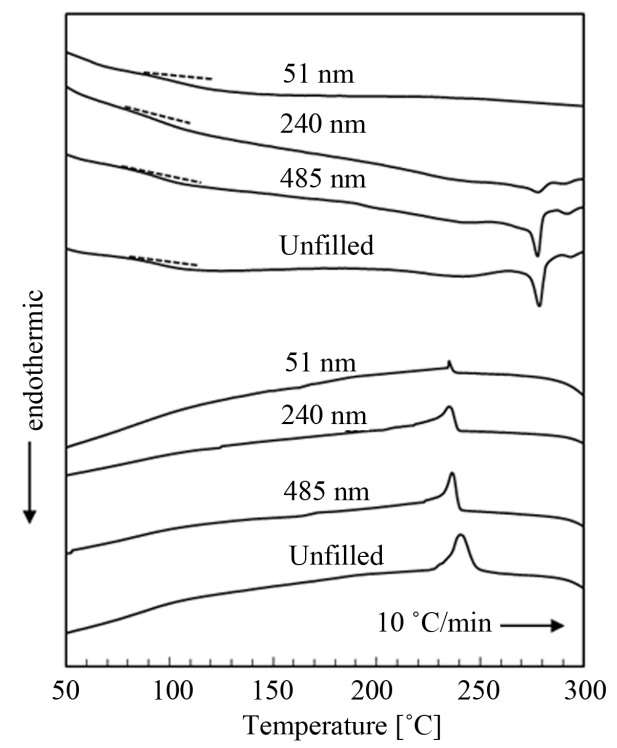

Figure 3. DSC curves of the composites of TLCP and SNPs with different diameters indicated in the figure. The weight fraction of SNPs was fixed to be $50 \%$. The sample designated as "Unfilled" indicates TLCP without SNPs. The 4 upper curves and 4 lower curves were obtained by heating and cooling measurements, respectively.

suggested from the results DSC, the XRD. Because around $100^{\circ} \mathrm{C}$ peak is corresponded with cooperative motions and glass transition, the results suggest that the presence of $51 \mathrm{~nm}$ SNP slow down the chain dynamics of TLCP thus increasing the glass transition. These results agree with those obtained from DSC. It is considered that the electrostatic interaction between negative charged carbonyl group and positive charged metal ions make TLCP chains tie up compared to the bulk state. This has been discussed about acrylate adhesives by IR analysis. [23]. 


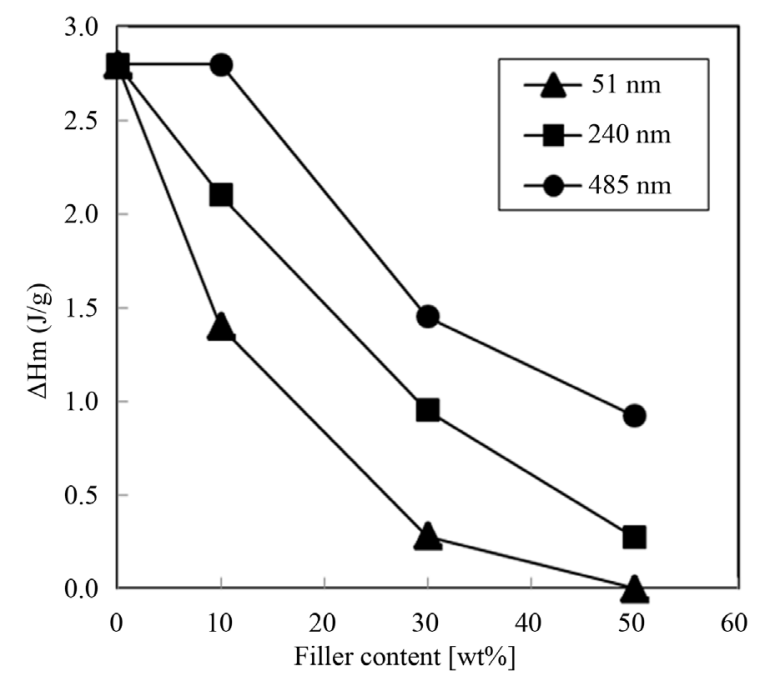

Figure 4. The heat of fusion detected for the composites at $230^{\circ} \mathrm{C}$.

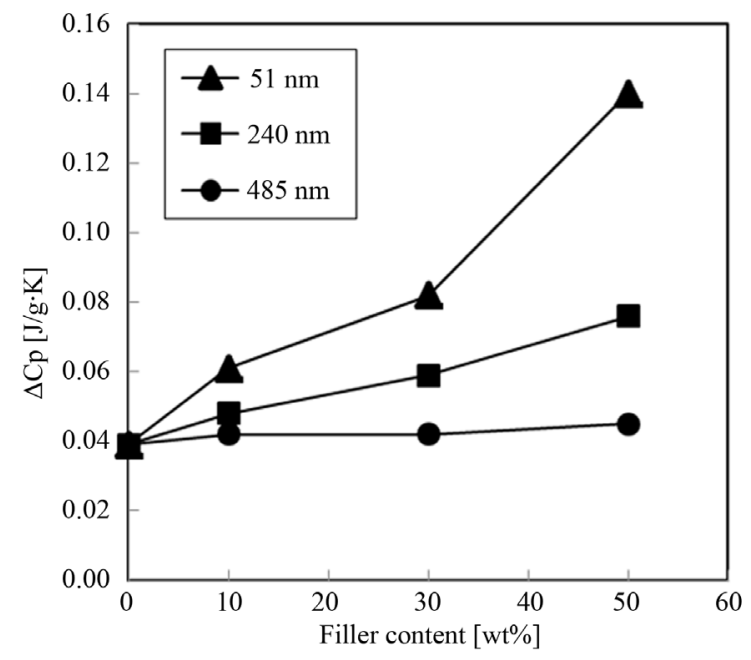

Figure 5. The change of the specific heat of Tg.

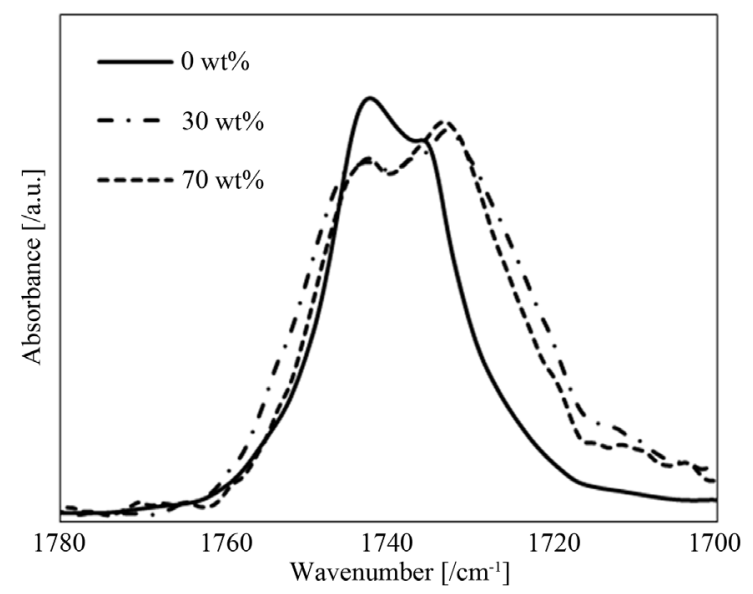

Figure 6. IR spectral changes in TLCP/SNPs (51 nm) composites. 


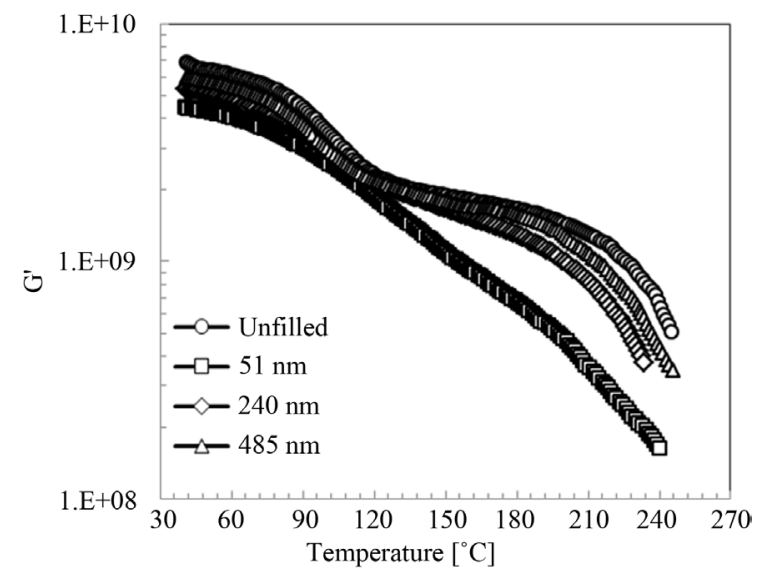

(a)

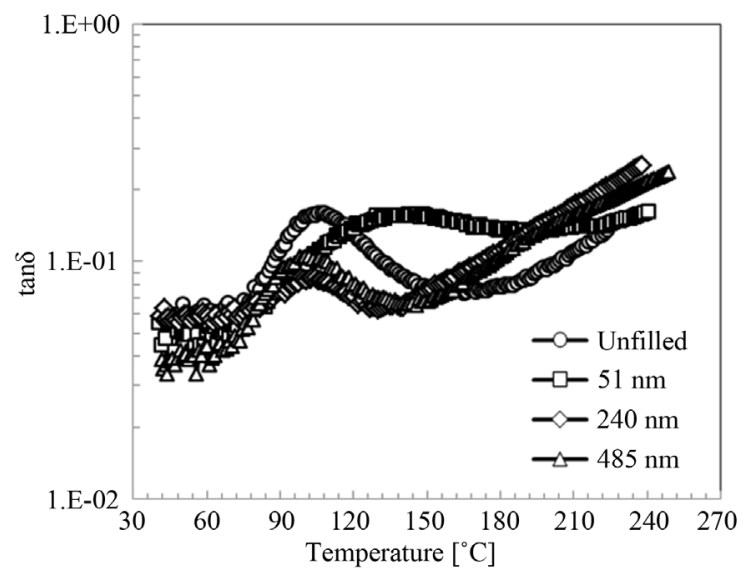

(b)

Figure 7. Temperature dependence of (a) storage modulus (G'); (b) tan $\delta$ of the composites of TLCP (0.7) and SNPs (0.3) with different diameters.

When the TLCP chains align parallel to the curved interface of SNPs, the TLCP chains are forced to bend along the curved interface of SNPs. This deformation makes it difficult for the TLCP chains to form crystal structure because the chains of the TLCP without SNPs have high rigidity. We have no definite evidence that the TLCP chains align parallel to the curved interface of SNPs at this time, but there have been many reports that polymer chains of other TLCPs in composites with GFs or CFs aligned parallel to the interface with fibers [8] [9]. The stronger effect for SNPs with smaller sizes to depress the crystallization can be explained by the increase of the surface area. The surface area per weight of SNPs with diameter of $51 \mathrm{~nm}$ is 4.7 times as large as that of SNPs with diameter of $240 \mathrm{~nm}$, and 9.5 times as large as that of SNPs with diameter of $485 \mathrm{~nm}$. The decrease of $\Delta \mathrm{Hm}$ for the composites of the TLCP and SNPs with diameters of $240 \mathrm{~nm}$ and $485 \mathrm{~nm}$ shown in Figure 4 can be explained by assuming that SNPs were completely dispersed in the composites, and that there are interfacial phase with thickness of over $100 \mathrm{~nm}$ where the TLCP cannot be crystallized. It is generally accepted that the thickness of interfacial phase between polymers and fillers is comparable to the dimension of a single polymer chain, and that the molecular mobility and structure of the polymers at this interfacial phase are different from those of the polymers at the bulk phase. The thick interfacial phase of the TLCP estimated in this study may be caused by the rigidity of the TLCP because rigid polymers usually have larger dimension than flexible polymers. The composite of SNPs with $51 \mathrm{~nm}$ has a small $\Delta \mathrm{Hm}$ value, which may be caused by the partial aggregation giving a decrease of the effective surface area of SNPs.

\section{Conclusion}

In this study, X-ray diffractometry (XRD) and differential scanning calorimetry (DSC) were carried out for composites of TLCP and SNPs with different diameters. Results show that the addition of SNPs to the composite of the TLCP and SNPs prevents the crystallization and induces the formation of amorphous regions of the TLCP, and that these tendencies became more significant when SNPs with smaller diameters were used for the sample preparation. This seems to make the strongly bended structure of TLCP molecules with distortion at the interface. The formation of these interfaces is important not only for physical interests, but also for the application of TLCPs as engineering plastics because the liquid crystalline structure dominates the mechanical properties of TLCPs.

\section{References}

[1] Sawyer, L.C., Linstid, H.C. and Romer, M. (1998) Emerging Applications for Neat LCPs. Plastics Engineering (N.Y.), 54, 37-41.

[2] Park, S.K., Kim, S.H. and Hwang, J.T. (2009) Effect of Fumed Silica Nanoparticles on Glass Fiber Filled Thermotropic Liquid Crystalline Polymer Composites. Polymer Composites, 30, 309-317. http://dx.doi.org/10.1002/pc.20557

[3] Voss, H. and Friedrich, K. (1986) Influence of Short-Fibre Reinforcement on the Fracture Behaviour of a Bulk Liquid 
Crystal Polymer. Journal of Materials Science, 21, 2889-2900. http://dx.doi.org/10.1007/BF00551508

[4] Chivers, R.A. and Moore, D.R. (1991) Influence of Fibre Reinforcement on the Mechanical Anisotropy of Liquid Crystal Polymers. Polymer, 32, 2190-2198. http://dx.doi.org/10.1016/0032-3861(91)90045-K

[5] Plummer, C.J.G., Zülle, B., Demarmels, A. and Kausch, H.-H. (1993) The Structure of Filled and Unfilled Thermotropic Liquid Crystalline Polymer Injection Moldings. Journal of Applied Polymer Science, 48, 751-766. http://dx.doi.org/10.1002/app.1993.070480501

[6] Scaffaro, R., Pedretti, U. and La Mantia, F.P. (1996) Effects of Filler Type and Mixing Method on the Physical Properties of a Reinforced Semirigid Liquid Crystal Polymer. European Polymer Journal, 32, 869-875. http://dx.doi.org/10.1016/0014-3057(96)00009-2

[7] Bhama, S. and Stupp, S.I. (1990) Liquid Crystal Polymer-Carbon Fiber Composites. Molecular Orientation. Polymer Engineering \& Science, 30, 228-234. http://dx.doi.org/10.1002/pen.760300406

[8] Lee, W.-G., Hsu, T.-C.J. and Su, A.C. (1994) Interphase Morphology of Liquid Crystalline Polymer/Glass Fiber Composites: Effect of Fiber Surface Treatment. Macromolecules, 27, 6551-6558. http://dx.doi.org/10.1021/ma00100a046

[9] Zhang, X., Tasaka, S. and Inagakim N. (2000) Surface Mechanical Properties of Low-Molecular-Weight Polystyrene below Its Glass-Transition Temperatures. Journal of Polymer Science Part B: Polymer Physics, 28, 654-658. http://dx.doi.org/10.1002/(SICI)1099-0488(20000301)38:5\%3C654::AID-POLB2\%3E3.0.CO;2-Z

[10] Zhang, X., Tasaka, S. and Inagaki, N. (2000) Studies on Surface Molecular Motion of Oligomeric Polystyrene by Differential Scanning Calorimetry. Polymers for Advanced Technologies, 11, 40-47. http://dx.doi.org/10.1002/(SICI)1099-1581(200001)11:1\%3C40::AID-PAT935\%3E3.0.CO;2-\%23

[11] Zhang, X., Tasaka, S. and Inagaki, N. (2003) Adhesion Behavior of Blends of Polybutadiene and Tackifiers. Journal of Adhesion Science and Technology, 17, 423-434. http://dx.doi.org/10.1163/156856103762864714

[12] Romo-Uribe, A. and Windle, A.H. (1996) "Log-Rolling” Alignment in Main-Chain Thermotropic Liquid Crystalline Polymer Melts under Shear: An In-Situ WAXS Study. Macromolecules, 29, 6246-6255. http://dx.doi.org/10.1021/ma960211h

[13] Kromer, H., Khun, R., Pielartzik, H., Siebke, W., Eckhardt, V. and Schmidt, M. (1991) Persistence Length and Molecular Mass Distribution of a Thermotropic Main-Chain Liquid-Crystal Polymer. Macromolecules, 24, 1950-1954. http://dx.doi.org/10.1021/ma00008a036

[14] Chivers, R.A., Blackwell, J. and Gutierrez, G.A. (1984) The Structure of Copoly(4-hydroxybenzoic acid/2-hydroxy6-naphthoic Acid): 2. An Atomic Model for the Copolyester Chain. Polymer, 25, 435-440. http://dx.doi.org/10.1016/0032-3861(84)90198-8

[15] Blackwell, J., Gutierrez, G.A. and Chivers, R.A. (1984) Diffraction by Aperiodic Polymer Chains: The Structure of Liquid Crystalline Copolyesters. Macromolecules, 17, 1219-1224. http://dx.doi.org/10.1021/ma00136a019

[16] Blackwell, J., Biswas, A. and Bonart, R.C. (1985) X-Ray Studies of the Structure of Liquid-Crystalline Copolyesters: Treatment of an Atomic Model as a One-Dimensional Paracrystal. Macromolecules, 18, 2126-2130. http://dx.doi.org/10.1021/ma00153a010

[17] Chivers, R.A. and Blackwell, J. (1985) Three-Dimensional Structure of Copolymers of p-Hydroxybenzoic Acid and 2-Hydroxy-6-Naphthoic Acid: A Model for Diffraction from a Nematic Structure. Polymer, 26, 997-1002. http://dx.doi.org/10.1016/0032-3861(85)90219-8

[18] Biswas, A. and Blackwell, J. (1987) X-Ray Diffraction from Liquid-Crystalline Copolyesters: Matrix Methods for Intensity Calculations Using a One-Dimensional Paracrystalline Model. Macromolecules, 20, 2997-3002. http://dx.doi.org/10.1021/ma00178a008

[19] Mitchell, G.R. and Windle, A.H. (1985) Diffraction from Thermotropic Copolyester Molecules. Colloid and Polymer Science, 263, 230-244. http://dx.doi.org/10.1007/BF01415509

[20] Gutierrez, G.A., Chivers, R.A., Blackwell, J., Stamatoff, J.B. and Yoon, H. (1983) The Structure of Liquid Crystalline Aromatic Copolyesters Prepared from 4-Hydroxybenzoic Acid and 2-Hydroxy-6-Naphthoic Acid. Polymer, 24, 937942. http://dx.doi.org/10.1016/0032-3861(83)90141-6

[21] Mitchell, G.R. and Windle, A.H. (1983) Measurement of Molecular Orientation in Thermotropic Liquid Crystalline Polymers. Polymer, 24, 1513-1520. http://dx.doi.org/10.1016/0032-3861(83)90164-7

[22] Achiha, O., Kyogoku, Y., Matsuda, Y. and Tasaka, S. (2012) Interfacial Structure of Composites of Poly( $m$-xylylen adipamide) and Silica Nano-Particles. Japanese Journal of Applied Physics, 51, 100204-1-3. http://dx.doi.org/10.1143/JJAP.51.100204

[23] Soga, I. and Granick, S. (2000) Segmental Orientations of Trains versus Loops and Tails: The Adsorbed Polymethylmethacrylate System When the Surface Coverage Is Incomplete. Colloids and Surface A, 170, 113-117. http://dx.doi.org/10.1016/S0927-7757(00)00409-X 